\title{
miR-210 Targets Iron-Sulfur Cluster Scaffold Homologue in Human Trophoblast Cell Lines
}

\section{Siderosis of Interstitial Trophoblasts as a Novel Pathology of Preterm Preeclampsia and Small-for-Gestational-Age Pregnancies}

\author{
Deug-Chan Lee, ${ }^{*}$ Roberto Romero, ${ }^{* \dagger \neq}$ \\ Jung-Sun Kim, ${ }^{\S}$ Adi L. Tarca, ${ }^{\star \Uparrow}$ \\ Daniel Montenegro, ${ }^{*}$ Beth L. Pineles, ${ }^{*}$ \\ Ernest Kim, ${ }^{*}$ JoonHo Lee, ${ }^{*}$ Sun Young Kim, ${ }^{*}$ \\ Sorin Draghici, ${ }^{\text {" }}$ Pooja Mittal, ${ }^{* \dagger}$ \\ Juan Pedro Kusanovic, ${ }^{* \dagger}$ \\ Tinnakorn Chaiworapongsa, ${ }^{* \dagger}$ Sonia S. Hassan, ${ }^{\star \dagger}$ \\ and Chong Jai Kim*\|

\begin{abstract}
From the Department of Health and Human Services," and Human Development, National Institutes of Health, Bethesda, Maryland, and Detroit, Michigan; the Departments of Obstetrics and Gynecology, ${ }^{\dagger}$ Computer Science, ${ }^{\text {"I }}$ and Pathology," and the Center for Molecular Medicine and Genetics, ${ }^{\ddagger}$ Wayne State University, Detroit, Michigan; and the Department of Pathology, ${ }^{\S}$ Samsung Medical Center, Sungkyunkwan University
\end{abstract} \\ Perinatology Research Branch, National Institute of Child Health \\ School of Medicine, Seoul, South Korea
}

This study was performed to assess the biological significance of miR-210 in preeclampsia and smallfor-gestational-age (SGA) pregnancies. Placental miR210 expression was evaluated by quantitative RT-PCR (RT-qPCR) in the following groups: i) appropriate-forgestational-age pregnancies $(n=72)$, ii) preeclampsia $(n=52)$, iii) SGA $(n=66)$, and iv)preeclampsia with SGA $(n=31)$. The effects of hypoxia $\left(1 \% \mathrm{O}_{2}\right)$ on miR-210 and iron-sulfur cluster scaffold homologue (ISCU) expressions and miR-210 binding to ISCU 3' UTR were examined in Swan 71 and BeWo cell lines. Perls' reaction $(n=229)$ and electron microscopy $(n=3)$ were conducted to verify siderosis of trophoblasts. miR-210 expression was increased in preeclampsia and SGA cases and was decreased with birth weight and gestational age. In both cell lines, miR-210 was induced by hypoxia, whereas ISCU expression was decreased. The luciferase assay con- firmed miR-210 binding to ISCU mRNA $3^{\prime}$ UTR. RNA interference knockdown of ISCU expression in Swan 71, but not in BeWo, cells resulted in autophagosomal and siderosomal iron accumulation and a fourfold decrease of Matrigel invasion $(P=0.004)$. Placental ISCU expression was decreased in preeclampsia ( $P=$ $0.002)$ and SGA $(P=0.002)$ cases. Furthermore, hemosiderin-laden trophoblasts were more frequent in the placental bed of preterm preeclampsia and/or SGA births than in control cases $(48.7 \%$ versus $17.9 \%$; $P=0.004)$. Siderosis of interstitial trophoblasts is a novel pathological feature of preeclampsia and SGA. The findings herein suggest that ISCU down-regulation by miR-210 perturbing trophoblast iron metabolism is associated with defective placentation. (Am J Pathol 2011, 179:590-602; DOI: 10.1016/j.ajpath.2011.04.035)

Preeclampsia is a major pregnancy disorder, affecting $5 \%$ to $8 \%$ of all pregnancies, and is associated with increased maternal and perinatal morbidity. ${ }^{1,2}$ This disorder clearly has features of systemic inflammation and endothelial dysfunction in the mother. ${ }^{3,4}$ Many studies ${ }^{5-7}$ have described changes of placental gene expression in pregnancies affected with preeclampsia, notably in-

Supported in part by the Perinatology Research Branch, Division of Intramural Research, Eunice Kennedy Shriver National Institute of Child Health and Human Development, NIH, Department of Health and Human Services.

Accepted for publication April 29, 2011

Address reprint requests to Roberto Romero, M.D., Perinatology Research Branch, National Institute of Child Health and Human Development, NIH, Department of Health and Human Services, Wayne State University, Hutzel Women's Hospital, 3990 John R. St., Detroit, MI 48201, or Chong Jai Kim, M.D., Ph.D., Department of Pathology, Wayne State University School of Medicine, Hutzel Women's Hospital, 3990 John R. St., 4 Brush, Room 4620, Detroit, Ml 48201. E-mail: prbchiefstaff@med.wayne. edu or cjkim@med.wayne.edu. 
creases in antiangiogenic molecules such as soluble endoglin and soluble fms-like tyrosine kinase 1. A sequence of events composed of shallow invasion of interstitial trophoblasts, impaired physiological transformation of maternal spiral arteries, and subsequent placental underperfusion has been described as a key pathological feature of preeclampsia. ${ }^{8-11}$ Huppertz ${ }^{12}$ recently defined these pathological consequences as particular features of early-onset preeclampsia, occurring before 34 weeks of gestation, in contrast to late-onset disease. Accordingly, placentas of preeclampsia cases display evidence of oxidative and endoplasmic reticulum stress, as is the case with fetal growth restriction. ${ }^{13,14}$ Small-for-gestational-age (SGA) births are commonly associated with preeclampsia, ${ }^{15}$ and this condition shares a fundamental pathological feature of superficial implantation of the placenta, a major characteristic of early-onset preeclampsia and SGA cases. ${ }^{9,12,16}$ Preeclamptic women are 3.6 times more likely to have SGA neonates compared with normotensive women. ${ }^{17}$

MicroRNAs (miRNAs) are small (21- to 23-nucleotide) single-stranded RNA molecules that play an important role in the post-transcriptional regulation of gene expression by promoting RNA instability or translational inhibition. ${ }^{18,19}$ Growing evidence indicates that miRNA expression profiles define clinicopathological phenotypes of various human disorders. ${ }^{20-26}$ Two recent studies ${ }^{27,28}$ have shown up-regulation of placental miR-210 as a distinct feature of preterm or severe preeclampsia, suggesting a role for miRNAs in the regulation of altered placental gene expression in preeclampsia. Not surprisingly, miR210 is known as a master miRNA of hypoxic response, a common component of the tumor microenvironment. miR-210 expression has been induced by hypoxia in all cell types tested ${ }^{29}$ in a hypoxia-inducible factor (HIF)- $1 \alpha-$ dependent manner. ${ }^{30}$ Moreover, in their recent analysis using Argonaute 2 immunoprecipitation, Huang et $\mathrm{al}^{31}$ also showed that $\mathrm{HIF}-1 \alpha$ regulates miR-210 expression in various tumors and that most of 50 potential target genes of miR-210 that were identified, such as HOXA1 and FGFRL1, are not hypoxia-inducible genes. The study clearly shows how HIF- $1 \alpha$ indirectly affects expression of genes through regulation of miR-210 expression. ${ }^{31}$

Preeclampsia and fetal growth restriction are more common in high-altitude regions. Zamudio et al ${ }^{32}$ indicated that pregnancy at high altitude $(3100 \mathrm{~m})$ and chronic hypoxia in vivo are associated with an increased expression of $\mathrm{HIF}-1 \alpha$, resembling that of preeclampsia. Therefore, up-regulation of miR-210 in preeclamptic placentas seems to be biologically relevant, yet functional targets of miR-210 in the placenta have not been identified. The present study was performed specifically to address the clinicopathological and functional significance of miR-210 in preeclampsia and SGA pregnancies across human gestation.

\section{Materials and Methods}

\section{Patients and Tissue Materials}

Tissue samples were retrieved from the Bank of Biological Materials of the Perinatology Research Branch, Eu- nice Kennedy Shriver National Institute of Child Health and Human Development, NIH, Department of Health and Human Services (Bethesda, MD, and Detroit, MI). All patients provided written informed consent for the collection of clinical data and tissue samples under protocols approved by the Institutional Review Boards of the participating institutions. For the analysis of miR-210 expression, placental paraffin blocks of term and preterm placentas $(N=221)$ from the following groups were retrieved: i) appropriate-for-gestational age (AGA) without preeclampsia $(n=72)$, ii) preeclampsia $(n=52)$, iii) SGA $(n=66)$, and iv) preeclampsia with SGA $(n=31)$. All patients were Hispanic women who were delivered of a neonate at Sótero del Rio Hospital, Santiago, Chile.

For localization of miR-210 expression by in situ hybridization, the placenta from a case of preterm preeclampsia with SGA (gestational age, 33.9 weeks) delivered at Hutzel Women's Hospital, Detroit, MI, was used. For immunoblotting of an iron-sulfur cluster scaffold homologue (ISCU), snap-frozen placental tissues from 12 preterm labor cases (median gestational age, 32.1 weeks; range, 24.6 to 34.4 weeks), 12 preterm preeclampsia with SGA $(n=2)$ or without SGA $(n=10)$ cases (median gestational age, 32.9 weeks; range, 23.9 to 35.0 weeks), and 12 preterm SGA cases (median gestational age, 31.6 weeks; range, 27.4 to 35.7 weeks), delivered at Sótero del Rio Hospital $(n=24)$ or Hutzel Women's Hospital $(n=12)$, were used. Among these cases, five were also included in the analysis of miR-210 expression $(n=4)$ or iron deposition in the placental bed $(n=1)$. There was no difference in the median gestational age among the groups.

For iron staining, placental sections obtained from 41 cases of preterm preeclampsia with SGA $(n=19)$ or without SGA $(n=22)$ among the cases tested for miR210 expression previously described were used, and placental bed biopsy materials were also retrieved from a different patient population $(N=229)$ whose placental bed biopsy specimens were available. All patients with placental bed biopsy specimens were delivered of a neonate at Hutzel Women's Hospital. The patient groups were as follows: i) AGA without preeclampsia $(n=121)$, ii) preeclampsia $(n=29)$, iii) SGA $(n=36)$, and iv) preeclampsia with SGA $(n=43)$. The placental bed was defined as biopsy specimens with proved superficial myometrium containing interstitial or endovascular trophoblasts.

Preeclampsia was defined as the new onset of hypertension after 20 weeks of gestation (systolic or diastolic blood pressure $\geq 140 \mathrm{~mm} \mathrm{Hg}$ or $\geq 90 \mathrm{~mm} \mathrm{Hg}$, respectively, measured at two different time points, 4 hours to 1 week apart), along with proteinuria ( $\geq 300 \mathrm{mg}$ in a 24-hour urine collection or two random urine specimens obtained 4 hours to 1 week apart containing $\geq 1+$ by dipstick or one dipstick demonstrating $\geq 2+$ protein). ${ }^{2,33}$ An SGA neonate was defined by sonography, with estimated fetal weight $<10^{\text {th }}$ percentile for gestational age and confirmed by neonatal birth weight. $^{34,35}$ 


\section{Real-Time RT-qPCR}

Ten serial paraffin curls (20- $\mu \mathrm{m}$ thick) were obtained in a 1.5-mL Eppendorf tube (Thermo Fisher Scientific, Waltham, MA) and deparaffinized using xylene. Total RNA was isolated using the RecoverAll Total Nucleic Acid Isolation Kit (Ambion Inc., Austin, TX), according to the manufacturer's instructions. RNA concentrations were measured using a NanoDrop spectrophotometer (Thermo Fisher Scientific). The total RNA of Swan 71 and BeWo cell lines was isolated with TRI Reagent (Ambion Inc.). For the relative quantification of miR-210 in placental tissues, $25 \mathrm{ng}$ of total RNA was reverse transcribed using the High Capacity cDNA Reverse Transcription Kit (Applied Biosystems, Framingham, MA); and the TaqMan MicroRNA Reverse Transcription Kit (Applied Biosystems) was used for RT of 100 ng of the total RNA of Swan 71 and BeWo cells. miR-210 expression was determined by using TaqMan assays (Applied Biosystems), and the TaqMan assay custom designed for 5 S ribosomal RNA (4373043) was used for normalization. Reactions were performed using a 7500 Fast Real-Time PCR System (Applied Biosystems).

\section{In Situ Hybridization}

In situ hybridization for the localization of miR-210 expression was performed using frozen placental sections (10- $\mu \mathrm{m}$ thick) obtained from a case of preterm preeclampsia with SGA delivered at the gestational age of 33.9 weeks. A double-labeled miR-210 locked nucleic acid (LNA) probe was generated by $3^{\prime}$-DIG labeling of a 5'-DIG-labeled miR-210 miRCURY LNA probe (Exiqon, Woburn, MA) using a DIG oligonucleotide tailing kit (Roche, Mannheim, Germany). After fixation in 4\% (w/v) paraformaldehyde for 10 minutes, the sections were acetylated using an acetylation solution $(0.1 \mathrm{~mol} / \mathrm{L}$ triethanolamine, $0.2 \% \mathrm{HCl}$, and $0.6 \%$ acetic anhydride). After proteinase $\mathrm{K}(5 \mu \mathrm{g} / \mathrm{mL})$ digestion for 5 minutes at room temperature, the sections were incubated with hybridization buffer [50\% formamide, $5 \times$ standard saline citrate, $5 \times$ Denhardt's solution, $200 \mu \mathrm{g} / \mathrm{mL}$ yeast RNA, 500 $\mu \mathrm{g} / \mathrm{mL}$ salmon sperm DNA, 2\% Roche blocking reagent, $0.25 \%$ 3-cholamidopropyl dimethylammonio-1-propanesulfonic acid (CHAPS), and $0.5 \%$ Tween 20] containing a $2 \mathrm{pmol} / \mathrm{L}$ probe for 5 minutes at $60^{\circ} \mathrm{C}$, with further hybridization overnight at $37^{\circ} \mathrm{C}$. The probes were denatured at $65^{\circ} \mathrm{C}$ for 5 minutes before application. After hybridization, the slides were washed with $0.2 \times$ standard saline citrate and $2 \%$ bovine serum albumin at $4{ }^{\circ} \mathrm{C}$ for 5 minutes, followed by incubation with 1:500 diluted alkaline phosphatase-conjugated anti-DIG antibody (Roche) at $37^{\circ} \mathrm{C}$ for 30 minutes. The signal was detected by using the Fast Red substrate system (Dako, Carpinteria, CA).

\section{In Vitro Hypoxia of Swan 71 Trophoblast and BeWo Choriocarcinoma Cell Lines}

Swan 71 human first-trimester trophoblast cells ${ }^{36}$ were maintained in Dulbecco's modified Eagle's medium (Mediatech Inc., Manassas, VA), and BeWo human choriocarcinoma cells (American Type Culture Collection, Manassas, VA) were cul- tured in F12 (GIBCO, Carlsbad, CA). Both culture media were supplemented with $10 \%$ fetal bovine serum (GIBCO). The cells were exposed to hypoxia for 24 or 48 hours using a gas mixture $\left(5 \% \mathrm{CO}_{2}\right.$ and $1 \% \mathrm{O}_{2}$ balanced with $\left.\mathrm{N}_{2}\right)$ in an automated ProOx 110 and $\mathrm{ProCO}_{2}-110$ controller-sealed hypoxia chamber (BioSpherix, Lacona, NY). Cells were harvested for RNA and protein isolation to assess the effects of hypoxia on miR-210 and ISCU expression.

\section{Immunoblotting}

Total protein was obtained from liquid nitrogen-pulverized snap-frozen placental tissues $(n=36)$ or from Swan 71 and BeWo cells using a radioimmunoprecipitation assay lysis buffer (Sigma-Aldrich, St. Louis, MO) containing a proteinase inhibitor cocktail (Roche). Protein, $10 \mu \mathrm{g}$, was electrophoresed in a $12 \%$ SDS-PAGE gel (Bio-Rad, Hercules, CA) and electroblotted to polyvinylidene difluoride membranes (Hybond-P; GE Healthcare Life Sciences, Piscataway, NJ). After blocking with $5 \%$ blotting grade blocker nonfat dry milk (Bio-Rad), the membranes were probed with a rabbit polyclonal antiISCU1/2 antibody (sc-28860; Santa Cruz Biotechnology Inc., Santa Cruz, CA), an anti-HPRT (hypoxanthine phosphoribosyltransferase) antibody (sc-20795; Santa Cruz Biotechnology Inc.), or a mouse monoclonal anti- $\beta$-actin antibody (A2228; Sigma-Aldrich). The chemiluminescent signals were detected using a ChemiGlow West kit (Alpha Innotech, San Leandro, CA).

\section{Luciferase Assay}

To assess miR-210 binding to the $3^{\prime}$ UTR of ISCU mRNA, the ISCU 3' UTR DNA fragment (289 bp) was amplified by PCR using human placental genomic DNA (forward primer: 5'-ATAATACTAGTCCAGCTGTTTCCCACCTGCTGTGCAGTC-3'; reverse primer: 5'-ATAATAAGCTTGGTAAAATTAGATACTTATGCACTTCAC-3') and cloned into the pGEM-T easy vector (Promega, Madison, WI). The sequence confirmed that the fragment was subcloned into the pMIR-REPORT Reporter Vector (Ambion Inc.). For the luciferase assay, $5 \times 10^{5}$ Swan 71 or BeWo cells were split in 60-mm cell culture dishes and cotransfected with $10 \mathrm{nmol} / \mathrm{L}$ miR-210 precursor molecules or miRNA precursor molecule-negative control 1, pMIR-ISCU 3' UTR, and pRL-SV40 (Promega) plasmid. Twenty-four hours after transfection, Firefly and Renilla luciferase activities were measured using the Dual-Luciferase Assay Reagent II (Promega). All experiments were performed three times, and Firefly luciferase activity was normalized to the activity of the Renilla luciferase.

\section{Transfection of Pre-miR-210 or Knockdown of ISCU by RNA Interference}

To determine the effects of miR-210 on ISCU expression, $5.0 \times 10^{5}$ Swan 71 or BeWo cells were split in a $60-\mathrm{mm}$ cell culture dish and transfected with $10 \mathrm{nmol} / \mathrm{L}$ pre-miR210 (Ambion Inc.) using the siPORT NeoFX Transfection Agent (Ambion Inc.). Control cells were transfected with miRNA precursor molecule-negative control 1 (Ambion 
Table 1. Demographic and Clinical Characteristics of the Study Population: Placental miR-210 Expression in 221 Subjects

\begin{tabular}{lcccc}
\hline \multicolumn{1}{c}{ Characteristics } & AGA $(n=72)$ & SGA $(n=66)$ & $\begin{array}{c}\text { Preeclampsia } \\
(n=52)\end{array}$ & $\begin{array}{c}\text { Preeclampsia with SGA } \\
(n=31)\end{array}$ \\
\hline Maternal age (years) & $27(17-45)$ & $23(16-42)$ & $24(16-37)$ & $25(17-38)$ \\
Nulliparity* & $19(26.4)$ & $43(65.2)$ & $32(61.5)$ & $19(61.3)$ \\
Smoking $^{*}$ & $11(15.3)$ & $13(19.7)$ & $4(7.7)$ & $3(9.7)$ \\
Body mass index $\left(\mathrm{kg} / \mathrm{m}^{2}\right)$ & $24.2(19.0-29.5)$ & $22.2(17.4-28.5)$ & $24.1(18.9-39.2)$ & $24.3(17.3-35.7)$ \\
Gestational age at delivery & $38.6(28.1-41.6)$ & $39.1(27.4-41.4)$ & $37.3(27.3-41.0)$ & $36.3(26.3-40.1)$ \\
$\quad$ (weeks) & $3305(1140-4470)$ & $2560(640-2950)$ & $2840(880-4270)$ & $2040(570-2960)$ \\
Birth weight $(\mathrm{g})$ & & & &
\end{tabular}

Data are given as median (range) unless otherwise indicated.

*Data are given as number (percentage) of subjects.

Inc.). Transfected cells were harvested after 24 hours, and protein lysates were obtained with a radioimmunoprecipitation assay lysis buffer (Sigma-Aldrich) for immunoblotting. For ISCU knockdown with the short hairpin RNA (shRNA) vector, $3.5 \times 10^{5}$ Swan 71 or BeWo cells were transfected with the pRS vector containing $\mathrm{HuSH}$ 29-mer anti-ISCU shRNA construct or pRS with a noneffective green fluorescent protein shRNA cassette (Origene, Rockville, MD) using a transfection reagent previously described. After 48 hours, the changes in ISCU protein expressions were evaluated by immunoblotting. Control and ISCU knocked-down Swan 71 or BeWo cells were subsequently subjected to Matrigel invasion assay (BD Bioscience, Sparks, MD), Perls' iron staining, and transmission electron microscopic examination.

\section{Matrigel Invasion Assay}

Matrigel was diluted to $20 \mu \mathrm{g} / \mathrm{mL}$ in cold PBS, and $100 \mu \mathrm{L}$ of diluted Matrigel was added to each insert (BD Bioscience) installed in a 24-well plate. Matrigel was allowed to polymerize for 4 hours at $37^{\circ} \mathrm{C}$. In each insert, $5 \times 10^{4}$ cells in $500 \mu \mathrm{L}$ of serum-free medium were seeded, and $500 \mu \mathrm{L}$ of medium with $5 \%$ fetal bovine serum were added to the wells containing the inserts. After 24 hours, the cells were fixed and stained using a Diff-Quik Stain
Set (Dade Behring Inc., Newark, DE). The number of cells that penetrated through Matrigel in each insert was counted in three high-power fields using an inverted microscope. The experiments were performed three times in duplicate.

\section{Perls' Reaction}

Hypoxia-exposed and anti-ISCU shRNA or control vector-transfected Swan 71 or BeWo cells were treated with ammonium iron citrate $(100 \mu \mathrm{g} / \mathrm{mL})$ for 24 hours. After fixation with $4 \%$ paraformaldehyde, the cells were stained with Perls' solution. For the enhancement of iron staining signals, the cells were incubated with $0.75 \mathrm{mg} / \mathrm{mL} 3,3^{\prime}-$ diaminobenzidine (Sigma-Aldrich) and $0.07 \% \mathrm{H}_{2} \mathrm{O}_{2}$ in 1 $\mathrm{mol} / \mathrm{L}$ Tris- $\mathrm{HCl}(\mathrm{pH} 7.5)$ for 5 minutes, followed by rinsing with PBS. For the demonstration of iron in the tissues, a Perls' reaction was performed with an iron staining kit (Richard-Allan Scientific, Kalamazoo, MI), according to the manufacturer's instructions, using formalin-fixed paraffin sections (5- $\mu \mathrm{m}$ thick).

\section{Transmission Electron Microscopy}

Hypoxia-exposed or ISCU knocked-down Swan 71 or BeWo cells for electron microscopic examination were
A

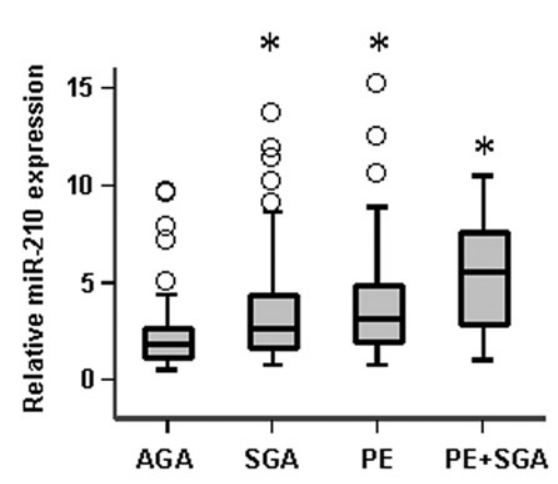

$\mathrm{B}$

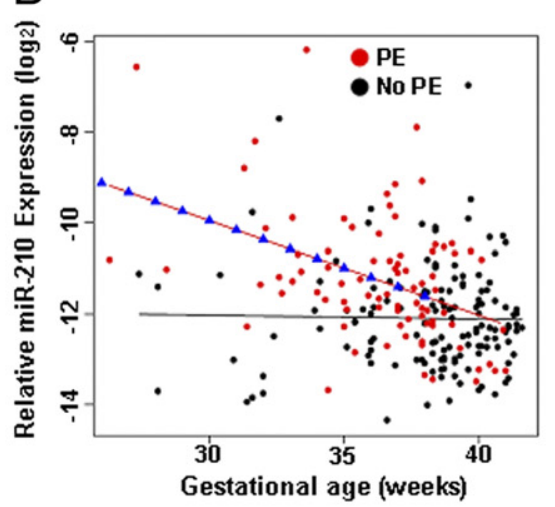

C

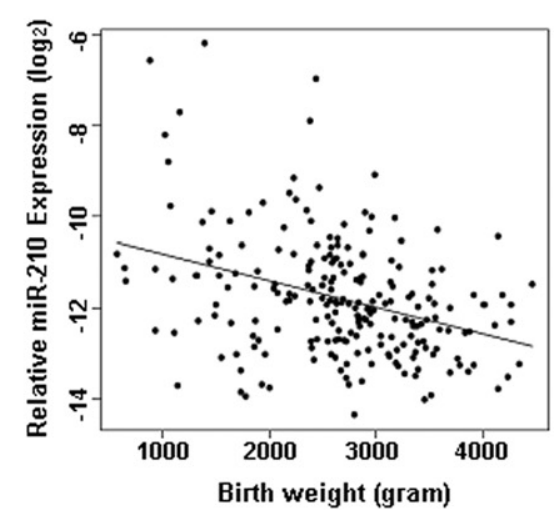

Figure 1. Placental expression of miR-210 determined by RT-qPCR. A: SGA, preeclampsia (PE), and PE with SGA pregnancies were associated with 1.6-, 1.9-, and 3.1-fold increases in placental miR-210 expression with respect to controls (AGA). ${ }^{*} P<0.01$ compared with AGA. B: A linear model showing higher placental miR-210 expression in PE cases between 26 and 38 weeks of gestation by $613 \%$ and $43 \%$, respectively, compared with those without PE ( $P<0.05$ ). There is no difference after 38 weeks of gestation. C: Inverse relationship between placental miR-210 expression and birth weight in combined cases with and without PE. For every kilogram increase in birth weight, miR-210 expression was decreased by approximately $35 \%(P<0.001)$. 
fixed with $1 \%$ glutaraldehyde solution. The cells were stained with $1 \% \mathrm{OsO}_{4}$ for 1 hour and then dehydrated through graded ethanol. After treatment with propylene oxide, the cells were subjected to epoxy resin infiltration. Placental bed tissues in paraffin blocks were deparaffinized using xylene and rehydrated through serial incubations in graded ethanol. After rinsing with distilled water, the samples were incubated with $0.1 \mathrm{~mol} / \mathrm{L}$ phosphate buffer ( $\mathrm{pH}$ 7.4). Deparaffinized samples were stained with $1 \% \mathrm{OsO}_{4}$ for 1 hour and then dehydrated through graded ethanol. Semi-thin sections of epoxy resin-embedded tissues were evaluated to locate the areas with interstitial trophoblasts, and ultra-thin sections were examined using a Hitachi 7100 transmission electron microscope (Hitachi High-Tech, Tokyo, Japan).

\section{Statistical Analysis}

The quantity $Y=-\left(C t_{\text {mir210 }}-C t_{\text {ref }}\right)$ was used as a surrogate for the log2 expression level of miR-210 in each of the 221 samples that were analyzed by RT-qPCR. A linear model was used to test for differences in miR-210 expression among patients with and without preeclampsia, adjusting for gestational age and birth weight at delivery. An interaction term was included in this model to assess whether the rate of change of miR-210 expression differed among clinical groups. A probability value was derived for each term included in the model to assess the significance of the estimated effects that were tested. All data analyses were performed using the $\mathrm{R}$ statistical environment (http://www.r-project.org). The Mann-Whitney U-test was used to compare the results of densitometry of ISCU

Table 2. Effect of Advancing Gestational Age and Preeclampsia on miR-210 Expression

\begin{tabular}{cccc}
\hline $\begin{array}{c}\text { Gestational age } \\
\text { (weeks) }\end{array}$ & Fold change & \% Change & $P$ value \\
\hline 26 & 7.13 & 613.35 & $<0.01$ \\
27 & 6.24 & 524.11 & $<0.01$ \\
28 & 5.46 & 446.03 & $<0.01$ \\
29 & 4.78 & 377.71 & $<0.01$ \\
30 & 4.18 & 317.95 & $<0.01$ \\
31 & 3.66 & 265.66 & $<0.01$ \\
32 & 3.20 & 219.91 & $<0.01$ \\
33 & 2.80 & 179.89 & $<0.01$ \\
34 & 2.45 & 144.87 & $<0.01$ \\
35 & 2.14 & 114.24 & $<0.01$ \\
36 & 1.87 & 87.43 & $<0.01$ \\
37 & 1.64 & 63.98 & $<0.01$ \\
38 & 1.43 & 43.47 & $<0.01$ \\
39 & 1.26 & 25.52 & NS \\
40 & 1.10 & 9.82 & NS \\
41 & 0.96 & -3.92 & NS \\
42 & 0.84 & -15.94 & NS \\
\hline
\end{tabular}

miR-210 expression in placentas with preeclampsia is increased between 26 and 38 weeks of gestation by $613 \%$ and $43 \%$, respectively, compared with those without preeclampsia. The magnitude of change in miR-210 expression between groups decreases with advancing gestation. The percentage change indicates an increase or decrease in miR210 expression in placentas of patients with preeclampsia versus those without preeclampsia. The differences reported are adjusted for birth weight at delivery. Therefore, they represent differences between groups at similar birth weights.

NS, not significant.
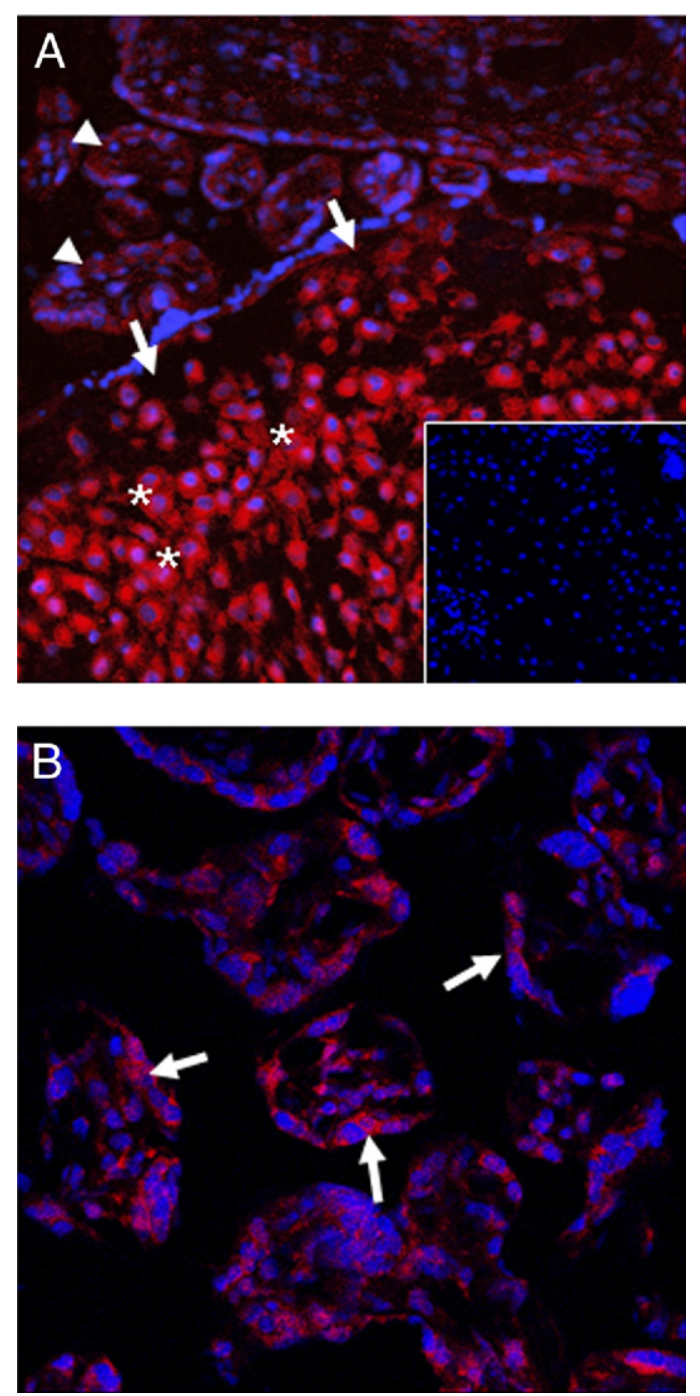

Figure 2. Localization of miR-210 expression by in situ hybridization. A Strong miR-210 hybridization signals are detected in the interstitial trophoblasts (asterisks) of the basal plate (arrows). Hybridization signals are stronger in the interstitial trophoblasts compared with those of villous trophoblasts (arrowheads). Inset: Negative control (hybridization with scramble control probe). B: In the chorionic villi, the miR-210 hybridization signal is readily seen in the syncytiotrophoblast layer (arrows). Weak hybridization signals are also detected in villous stromal cells and capillary endothelial cells

expression, luciferase assay, and Matrigel invasion assay. Comparisons of positivity for Perls' reaction in placental bed biopsy specimens between the control and preeclampsia/SGA groups were performed using a $\chi^{2}$ or Fisher's exact test. $P<0.05$ was considered significant in all comparisons.

\section{Results}

\section{Placental miR-210 Expression: Preeclampsia, Birth Weight, and Gestational Age}

The demographic characteristics of the study population are summarized in Table 1. SGA, preeclampsia, and preeclampsia with SGA pregnancies were associated 
A
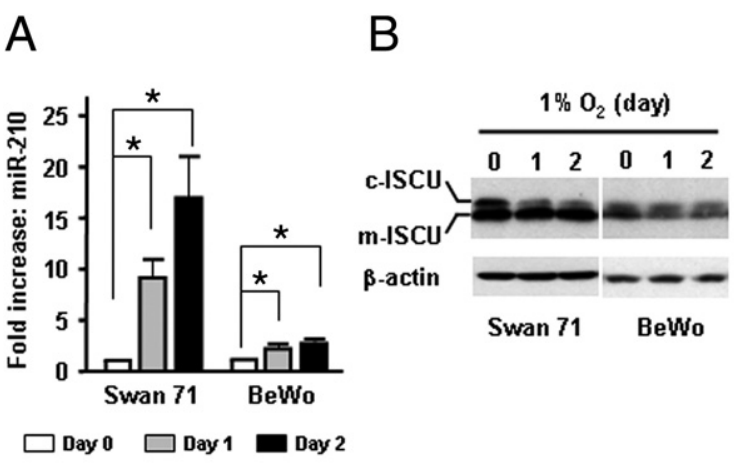

D

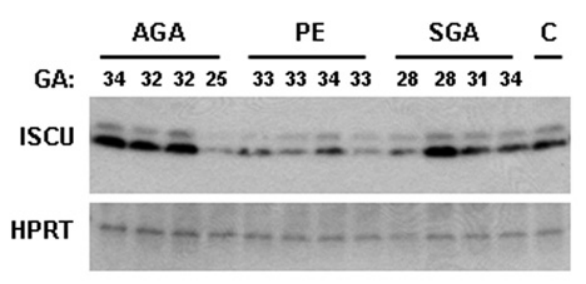

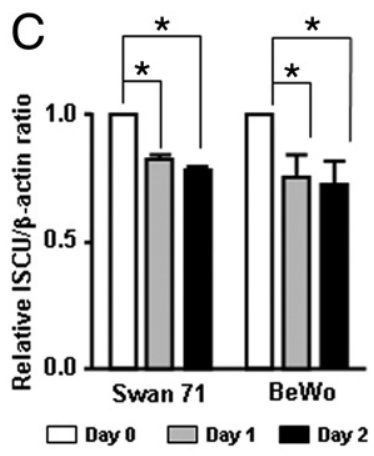

E

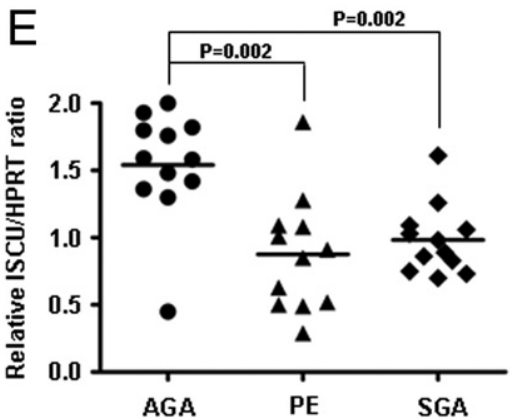

Figure 3. miR-210 and ISCU expression in trophoblast cell lines and placentas. A: Increased expression of miR-210 by hypoxia $\left(1 \% \mathrm{O}_{2}\right)$ in Swan 71 human first-trimester trophoblast cells and BeWo choriocarcinoma cells. miR-210 expression is increased by 8.9 - and 2.1-fold after 24 hours of hypoxia in Swan 71 and BeWo cells respectively ( ${ }^{*} P<0.05$ for each). B: Immunoblotting of hypoxia-treated Swan 71 and BeWo cells showing decreased expression of both isoforms of ISCU. The change is more prominent in cytosolic ISCU (c-ISCU) than in mitochondrial ISCU (m-ISCU). C: Densitometric analysis of ISCU expression shows a significant decrease of ISCU in hypoxia-treated Swan 71 and BeWo cells. D: Immunoblotting analysis showing decreased ISCU expression in villous placental tissues obtained from preeclampsia (PE) and SGA cases $(P=0.002$ for each). E: Densitometric analysis of immunoblotting shows that ISCU expression is significantly decreased in PE and SGA cases. Two cases in the PE group had concomitant SGA. The SGA group represents all isolated cases without preeclampsia. All cases are preterm cases. For densitometric analysis, the sum of both cellular and mitochondrial ISCU signals was compared. GA indicates gestational age (weeks) at delivery; C, internal control. with 1.6-, 1.9-, and 3.1-fold increases in placental miR210 expression when compared with controls, respectively (Figure 1A). The linear model showed that placental miR-210 expression is significantly higher in preeclampsia cases between 26 and 38 weeks of gestation by $613 \%$ and $43 \%$, respectively, compared with those without preeclampsia ( $P<0.05$; Table 2 and Figure 1B), but not after 38 weeks of gestation. The magnitude of the difference in miR-210 expression between preeclampsia and nonpreeclampsia groups decreased with advancing gestation, which was explained by increments in miR-210 expression at a rate of $8.6 \%$ per week in cases without preeclampsia and decrements in miR-210 expression at a rate of $5.0 \%$ per week in preeclampsia cases. Placental miR-210 expression is inversely related to birth weight in patients with and without preeclampsia. For every kilogram increase in birth weight, miR-210 expression was decreased by approximately 35\% $(P<0.001$, Figure 1C).

\section{Hypoxia-Inducible miR-210 Targets ISCU in Swan 71 Trophoblast and BeWo Choriocarcinoma Cell Lines}

In situ hybridization using an LNA probe specific for miR210 showed that miR-210 is primarily expressed in both villous trophoblasts and extravillous interstitial trophoblasts, with far more distinct fluorescence in the latter (Figure 2A). Weak miR-210 hybridization signals were also detected in villous stromal cells and capillary endothelial cells (Figure 2B). Because trophoblasts are the primary population of cells expressing miR-210, we further examined regulation of miR-210 by in vitro hypoxia using the Swan 71 trophoblast cell line, established from a human first-trimester placenta that has the character- istics of extravillous trophoblasts, ${ }^{36}$ and the BeWo choriocarcinoma cell line, used in vitro to mimic syncytialization. ${ }^{37,38}$

miR-210 expression increased 8.9- and 2.1-fold in Swan 71 and BeWo cell lines exposed to $1 \% \mathrm{O}_{2}$ for 24 hours, respectively ( $P<0.05$ for each, Figure 3A). A search for putative targets of miR-210 using the TargetScan tool (http://www.targetscan.org, last accessed January 5,2009$)$ revealed ISCU to be among the top-predicted targets of miR-210. Immunoblotting of Swan 71 and BeWo cell lines incubated in $1 \% \mathrm{O}_{2}$ showed decreased expression of predominantly the cytosolic isoform of ISCU after hypoxia (Figure 3, B and C). Furthermore, ISCU expression in primary villous placental tissues was decreased in preeclampsia and SGA cases $(P=0.002$ for each; Figure 3, D and $E)$.

Based on the consistent inverse correlation between miR-210 and ISCU expression patterns, a luciferase assay was conducted to determine whether miR-210 binds to the 3' UTR of ISCU mRNA in Swan 71 and BeWo cells. Transfection of Swan 71 and BeWo cells with pMIR-REPORT-ISCU 3' UTR and precursor miR-210 resulted in a $33 \%$ and $29 \%$ reduction in luciferase activity, respectively, indicating that miR-210 binds to ISCU 3' UTR in both cell lines $(P<0.05$ for each, Figure 4A). Transfection of Swan 71 and BeWo cells with precursor miR-210 also decreased both cytosolic and mitochondrial isoforms of ISCU expression (Figure 4B). Experiments were also performed to assess whether ISCU knockdown could result in intracellular iron accumulation in trophoblasts. Transfection of Swan 71 and BeWo cells with anti-ISCU shRNA significantly decreased ISCU protein expressions (Figure 5, A and B) and resulted in coarsely granular cytoplasmic iron accumulation only in ISCUinhibited Swan 71 cells but not in BeWo cells, compared 
A

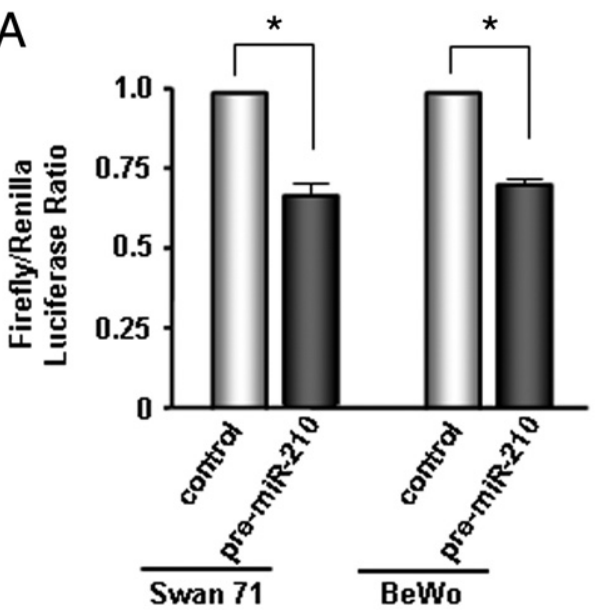

\section{ISCU3'UTR-binding site (position 111-117)}

Homo sapiens 5' GAAGAGCUAUGAGAUACGCACAA

Hsa-miR 210 3'AGUCGGCGACAGUG--UGCGUGUC

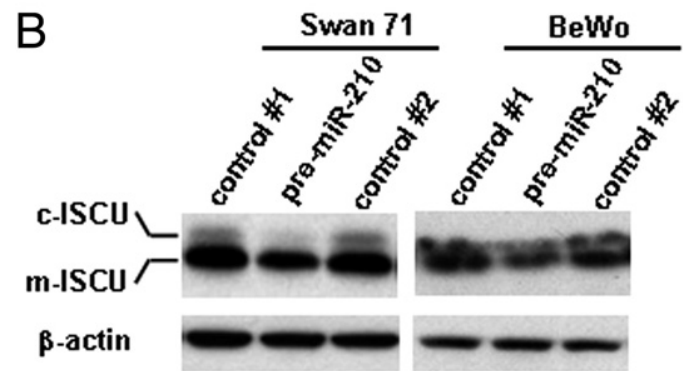

Figure 4. miR-210 binding to ISCU mRNA $3^{\prime}$ UTR in Swan 71 and BeWo cell lines. A: Transfection of Swan 71 and BeWo cells with pMIR-REPORT-ISCU 3' UTR and precursor miR-210 resulted in a 33\% and $29 \%$ reduction in luciferase activity compared with the control group, respectively $(* P<0.05$ for each). B: Transfection of Swan 71 and BeWo cells with precursor miR-210 also decreases the expression of both cytosolic (c-) and mitochondrial (m-) isoforms of ISCU. Swan 71 and BeWo cells were transfected with distilled water (control 1), precursor miR-210 (premiR-210), or miRNA precursor molecules-negative control (control 2)

with corresponding control cells after ammonium iron citrate $(100 \mu \mathrm{g} / \mathrm{mL}$ ) treatment for 24 hours (Figure 5, A and $\mathrm{B}$ ). Swan 71 cells exposed to $1 \% \mathrm{O}_{2}$ also showed similar intracellular iron deposits but not in BeWo cells (data not shown). For intracellular localization of iron accumulation, electron microscopic examination of hypoxiatreated and ISCU knocked-down Swan 71 cells was performed. Iron was observed as electron-dense deposits in membrane-bound lysosomes (siderosomes), whereas mitochondrial iron deposition was not evident in hypoxiatreated Swan 71 cells (Figure 5, C and D). Interestingly, however, a few autophagosomes containing organelles with electron-dense deposition were observed in the perinuclear regions of ISCU knocked-down Swan 71 cells (Figure 5, E and F). The autophagosomes were not found in BeWo cells (Figure 5, G and $\mathrm{H}$ ).

Furthermore, the Matrigel invasion assay demonstrated a $412 \%$ decrease in invasiveness of Swan 71 cells when ISCU is knocked down by shRNA, compared with the control cells $(P=0.004$; Figure $6, A$ and $B)$.
BeWo cells did not invade Matrigel, as expected; therefore, the effects of ISCU knockdown could not be compared (Figure 6B).

\section{Assessment of Iron Deposition in Trophoblasts}

Intracellular accumulation of free iron has been documented in relatively rare human diseases originating from defective iron-sulfur (Fe-S) cluster biogenesis. ${ }^{39-42}$ To determine whether intracellular iron accumulation could be found in trophoblasts of preeclampsia and SGA cases, we examined placental sections obtained from 41 cases of preterm preeclampsia with SGA $(n=19)$ or without SGA $(n=22)$, among the cases (Table 1) in which miR-210 expression was assessed by RT-qPCR. However, none of these cases showed iron deposition in villous trophoblasts when Perls' reaction was performed using formalin-fixed, paraffin-embedded sections. Instead, focal punctate iron deposition in villous stromal
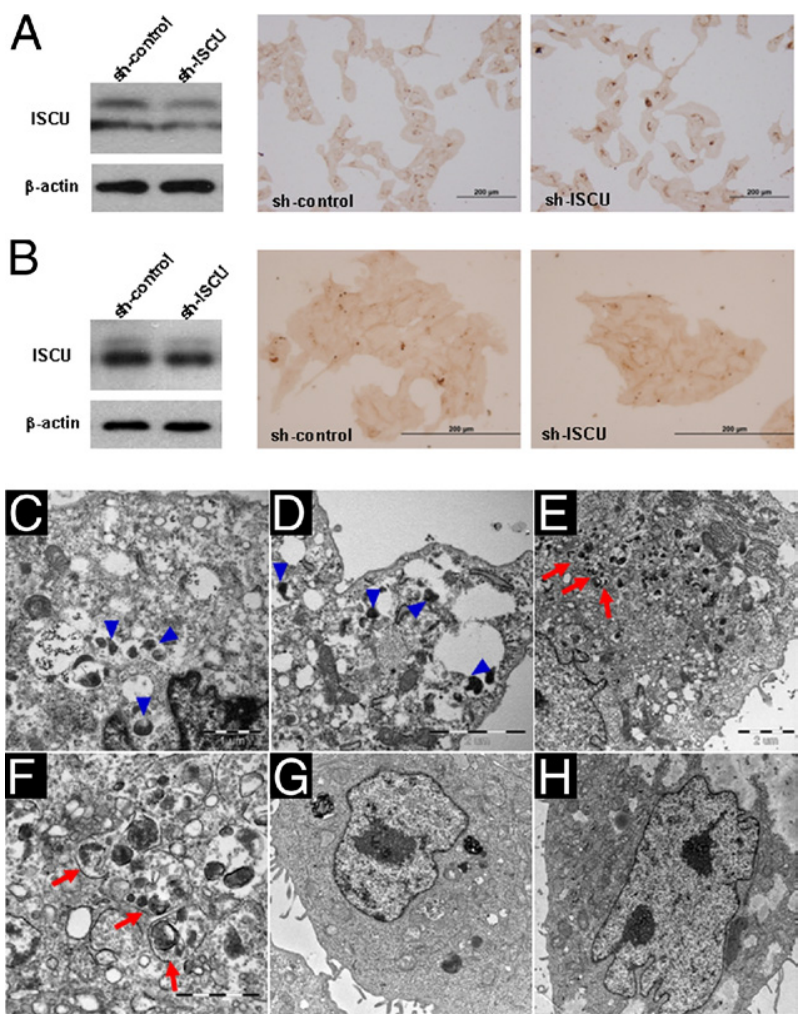

Figure 5. Intracellular iron deposition in ISCU knocked-down or hypoxiatreated Swan 71 and BeWo trophoblast cells. A: Immunoblotting showing decreased ISCU expression by anti-ISCU shRNA transfection. Granular cytoplasmic iron deposition is a characteristic of ISCU-inhibited Swan 71 cells. The cells were treated with ammonium iron citrate $(100 \mu \mathrm{g} / \mathrm{mL})$ for 24 hours. Swan 71 cells exposed to $1 \% \mathrm{O}_{2}$ also showed similar intracellular iron deposits (data not shown). B: ISCU knockdown was not associated with increased iron deposition in BeWo cells. Hypoxia $\left(1 \% \mathrm{O}_{2}\right)$ also was not associated with changes in iron deposition (data not shown). C-F: Ultrastructural features of hypoxia-treated $(\mathbf{C}$ and $\mathbf{D})$ and ISCU knocked-down (E and F) Swan 71 cells showing electron-dense deposits in membrane-bound lysosomes (siderosomes; arrowheads). Mitochondrial electron-dense deposits were not evident, but autophagosomes (arrows) containing organelles with electron-dense deposits were detected in the perinuclear region of ISCU knocked-down Swan 71 cells. G and $\mathbf{H}$ : In BeWo cells, neither hypoxia (G) nor ISCU (H) knockdown resulted in an increase of autophagosomes or siderosomes. 
A

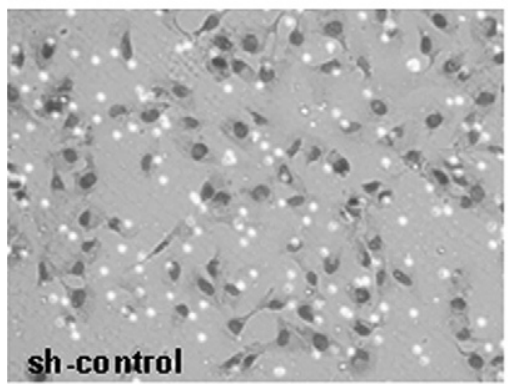

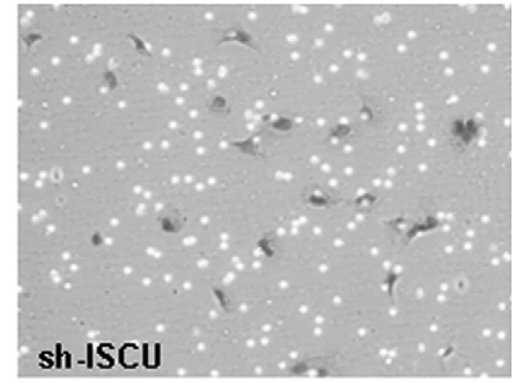

B

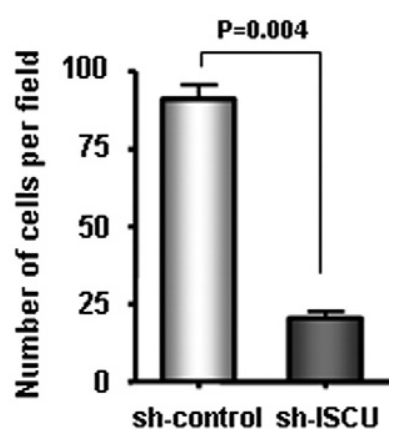

Figure 6. Decreased Matrigel invasion of Swan 71 trophoblasts. A: There is a marked decrease of Matrigel invasion in ISCU knocked down by shRNA compared with the control cells. B: A graph displaying a $412 \%$ decrease in invasiveness of ISCU knocked-down Swan 71 cells compared with control cells $(P=0.004)$.

cells or Hofbauer cells was found in two cases of preterm preeclampsia with SGA (Figure 7, A and B).

Based on the observation of in vitro (Swan 71 versus BeWo cells) and villous placental iron staining patterns, we further studied iron deposition in extravillous trophoblasts using placental bed biopsy specimens available from an independent cohort of patients $(n=229)$ who represented preeclampsia, SGA, and control groups. The demographics of this group of patients are summarized in Table 3.

Perls' reaction demonstrated intracellular hemosiderin deposits in interstitial trophoblasts. These interstitial tro-
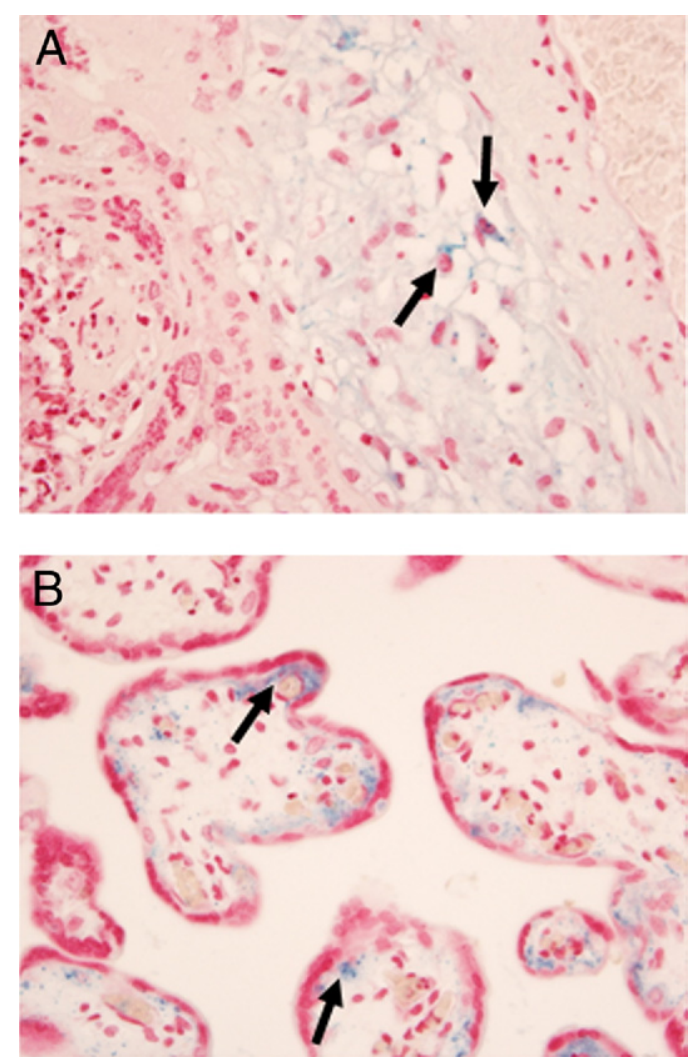

Figure 7. Iron deposition patterns in the villous placenta of preterm preeclampsia cases with SGA. A: Punctate cytoplasmic iron deposition in stromal and Hofbauer cells sp (arrows) of a stem villus embedded in a recent infarct at the gestational age of 31.4 weeks. B: Another case showing punctate and lacy Perls' reaction in the villous stroma (arrows). The case was delivered at the gestational age of 35.0 weeks. phoblastic iron deposits were more prominent in placental-site giant cells, and they appeared as crystalloid cytosolic aggregations on Perls' reaction (Figure 8, A and $B$ ). The proportion of iron-positive cases was significantly different between preeclampsia or SGA and gestational age-matched nonpreeclamptic AGA cases $(P=0.015)$. A hemosiderin deposit was found in 48 (44.4\%) of 108 cases of preeclampsia or SGA and 35 (28.9\%) of 121 gestational age-matched nonpreeclamptic AGA cases. When the cases were divided into preterm $(n=106)$ and term ( $n=123)$ cases, trophoblastic hemosiderin deposition was more frequently found in preeclampsia or SGA cases compared with control cases in preterm cases [48.7\% (38/78) versus $17.9 \%(5 / 28) ; P=0.004]$, whereas the difference was not statistically significant in term cases [33.3\% (10/30) versus 32.3\% (30/93)] (Figure 8C).

Transmission electron microscopy was performed in a group of preeclampsia or SGA cases $(n=3)$ to identify the intracellular location (mitochondria versus cytosol) of iron deposition. As was seen in Swan 71 cells, round to oval, membrane-bound, electron-dense siderosomes were found in the cytoplasm of trophoblasts (Figure 9), whereas iron deposits were not observed in mitochondria. In contrast to Swan 71 cells, autophagosomes were not detected in interstitial trophoblasts under examination.

\section{Discussion}

The primary findings of this study are as follows: i) placental expression of miR-210 increases in preeclampsia and is inversely related to birth weight and gestational age; ii) hypoxia-inducible miR-210 targets 3' UTR of ISCU mRNA in Swan 71 and BeWo trophoblast cell lines; iii) hypoxia $\left(1 \% \mathrm{O}_{2}\right)$ or ISCU knockdown results in siderosomal iron accumulation and the formation of autophagosomes in Swan 71 trophoblast cells with extravillous trophoblast characteristics but not in BeWo cells with a potential for syncytialization; iv) ISCU knockdown markedly decreases Matrigel invasion of Swan 71 cells; v) iron deposition was not observed in villous trophoblasts of placental tissues obtained from preterm preeclampsia, with or without SGA cases $(n=41)$; and vi) hemosiderin deposition in the interstitial trophoblasts at the placental bed is more frequent in preterm, but not term, preeclampsia or SGA pregnancies compared with control cases. 
Table 3. Demographic and Clinical Characteristics of the Study Population: Siderosis of Interstitial Trophoblasts in the Placenta Bed in 229 Subjects

\begin{tabular}{lcccc}
\hline \multicolumn{1}{c}{ Characteristics } & AGA $(n=121)$ & SGA $(n=36)$ & $\begin{array}{c}\text { Preeclampsia } \\
(n=29)\end{array}$ & $\begin{array}{c}\text { Preeclampsia with SGA } \\
(n=43)\end{array}$ \\
\hline Maternal age (years) & $25(18-41)$ & $26(15-42)$ & $28(16-41)$ & $24(15-43)$ \\
Race & & & & \\
Black & $108(89.3)$ & $31(86.1)$ & $5(79.3)$ & $40(93.0)$ \\
White & $6(5.0)$ & $2(5.6)$ & $0(0)$ & $2(0)$ \\
$\quad$ Hispanic & $2(1.7)$ & $2(5.8)$ & $1(3.4)$ & $1(2.3)$ \\
$\quad$ Other & $5(4.1)$ & $15(41.7)$ & $14(48.3)$ & $15(34.9)$ \\
Nulliparity & $30(24.8)$ & $11(30.6)$ & $4(13.8)$ & $7(16.3)$ \\
Smoking & $20(16.5)$ & $31.5(20.3-55.8)$ & $36.5(19.0-65.1)$ & $35.0(20.4-55.4)$ \\
Body mass index (kg/m $)^{*}$ & $36.0(22.1-64.1)$ & $30.9(23.9-39.0)$ & $31.7(24.0-40.6)$ \\
Gestational age at delivery & $39.0(23.4-42.0)$ & $37.1(24.4-40.4)$ & & \\
$\quad$ (weeks) & & & $1425(640-3765)$ & $1360(327-2530)$ \\
Birth weight $(\mathrm{g})^{*}$ & $3215(530-3935)$ & $2430(350-2830)$ & & \\
\hline
\end{tabular}

Data are given as number (percentage) of subjects unless otherwise indicated.

*Data are given as median (range).

Iron is essential for eukaryotic metabolism by serving as a cofactor in various cellular processes, such as respiration, oxygen transport, and DNA repair. ${ }^{43,44} \mathrm{Fe}-\mathrm{S}$ clusters are prosthetic groups present in all life forms, and the $2 \mathrm{Fe}-2 \mathrm{~S}$ and $4 \mathrm{Fe}-4 \mathrm{~S}$ clusters are common types. These clusters, containing tetrahedrally coordinated iron atoms and bridging sulfides, accept or donate single electrons and thereby function as cofactors or regulatory proteins. ${ }^{45}$ Because Fe-S clusters play a critical role in a wide range of cellular activities, such as electron transfer in oxidative phosphorylation and catalysis of enzymatic reactions, ${ }^{46-48}$ perturbations in their biogenesis and repair are detrimental to the cells. The critical nature of Fe-S cluster biogenesis is evidenced by examples of human disorders due to mutations of the genes involved in Fe-S cluster biogenesis. Autosomal-recessive Friedreich's ataxia is a neurodegenerative disorder caused by a loss of frataxin in the mitochondria. An intronic GAA triplet expansion in the frataxin-encoding gene impedes transcription elongation of frataxin, thus leading to its deficiency. ${ }^{39,49}$ Sideroblastic anemia cases have a mutation in the glutaredoxin- 5 gene and subsequent mitochondrial iron overload. ${ }^{40}$ Swedish myopathy is a disorder in which
ISCU expression is markedly decreased because of an intronic G to $\mathrm{C}$ mutation in ISCU. This disorder is characterized by muscle weakness, exercise-induced myoglobinuria, and muscle iron overload. ${ }^{41,42}$ ISCU is a key protein involved in Fe-S cluster biogenesis, and isoforms originating from alternative splicing have been found in the mitochondria and the cytosol, indicating that Fe-S cluster biogenesis is a compartmentalized process in mammalian cells. ${ }^{48,50}$ Impairment of cytosolic Fe-S cluster assembly after selective depletion of cytosolic ISCU in HeLa cells indicated that its function cannot be compensated by mitochondrial ISCU.

Intracellular iron could be either heme or nonheme iron, which is stored in ferritin or hemosiderin. ${ }^{51}$ The distinct and strong Perls' reaction pattern in this study indicates nonheme iron accumulation, and ultrastructural patterns are consistent with siderosomes. It is particularly intriguing that iron deposition is found in lysosomes (siderosomes) but not in mitochondria of interstitial trophoblasts in the placental bed. Although all disorders of Fe-S cluster biogenesis previously described are characterized by punctate mitochondrial iron deposits, significant mitochondrial alterations were not found in the present
A

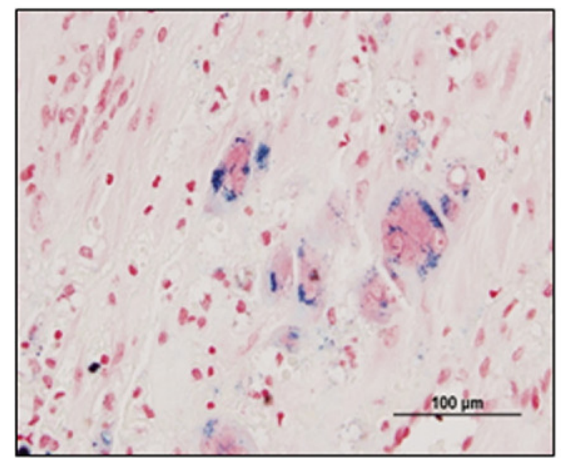

B

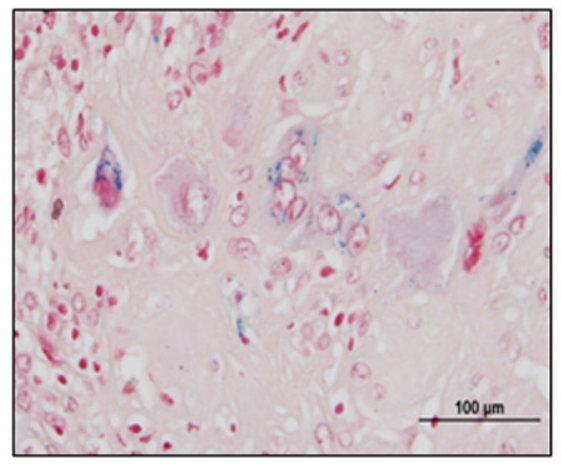

C

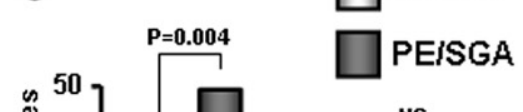

NS

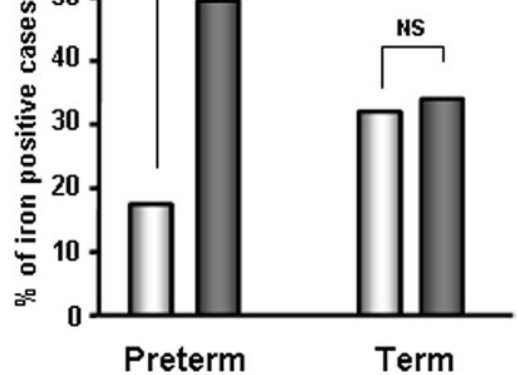

Figure 8. Iron deposition in interstitial trophoblasts of the placental bed of preeclampsia (A) and SGA (B) cases, both at the gestational age of 25 weeks. A and B: Perls' reaction showing intracellular hemosiderin deposits. The deposits are more prominent in placental-site giant cells, appearing as crystalloid cytosolic aggregations. Original magnification, $\times 400$. C: Hemosiderin in trophoblasts is more frequent in preeclampsia (PE)/SGA cases compared with control cases in preterm cases [48.7\% (38/78) versus $17.9 \%(5 / 28) ; P=0.004]$, whereas there is no difference in term cases [33.3\% (10/30) versus 32.3\% (30/93)]. NS indicates not significant. 

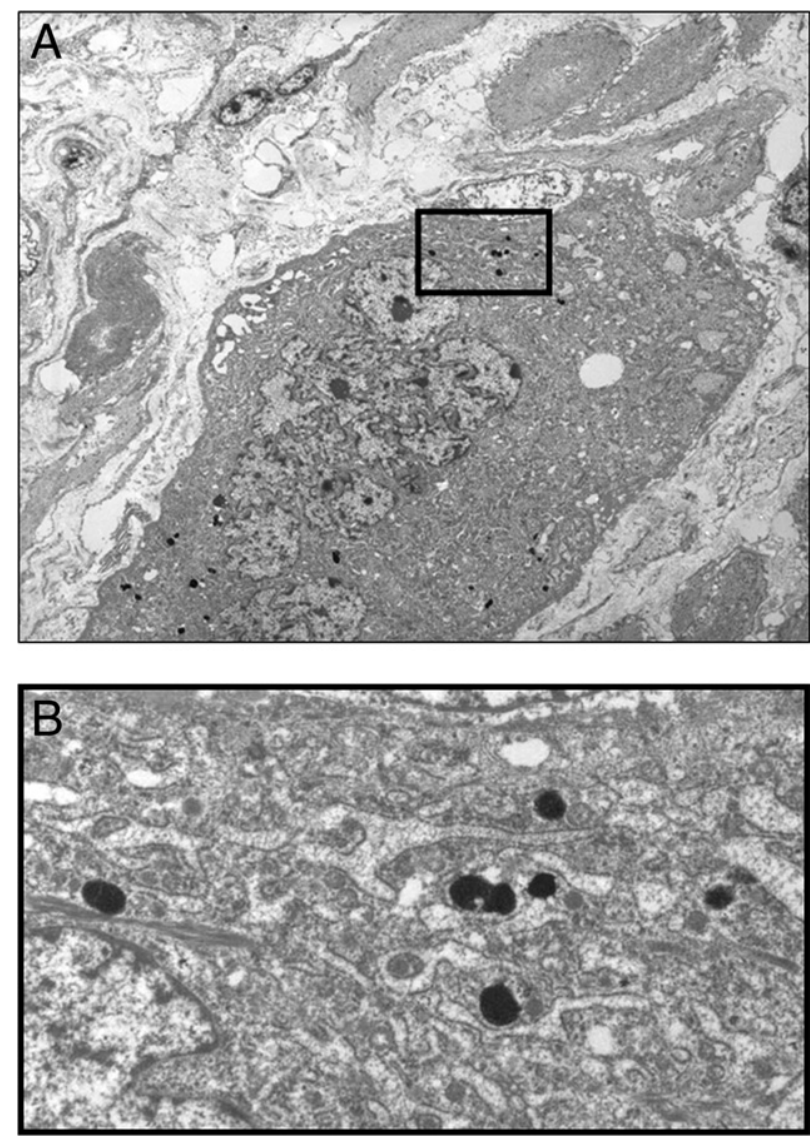

Figure 9. Transmission electron microscopy placental bed biopsy specimen from a preterm SGA case, shown in Figure 8B. A: Electron-dense lysosomal iron deposits (siderosomes) in the cytoplasm of interstitial trophoblasts are characteristic. Iron deposits are not observed in mitochondria. B: Close-up image of siderosomes in the box shown above in Figure 9A.

study both in vivo and in vitro. Mitochondria are the site of heme and Fe-S cluster biosynthesis and also store iron in mitochondrial ferritin. Mitochondria play a central role in the regulation and integration of iron metabolism between the mitochondria and cytosol. ${ }^{52}$ In Friedreich's ataxia, cytosolic iron is depleted because of increased expression of mitochondrial ferritin and subsequent mitochondrial iron overloading. ${ }^{53}$ Therefore, reconciliation of decreased placental ISCU expression and siderosomal iron deposition in the present study is an intriguing challenge. A recent study ${ }^{54}$ has shown increased autophagy in preeclamptic placentas. Therefore, Iysosomal uptake of ironcontaining macromolecules, such as ferritin and mitochondrial electron transport complex, by autophagy might be one possible explanation. ${ }^{55}$ Our observation of Swan 71 cells showing autophagosomes containing membranebound iron-laden organelles after ISCU knockdown strongly supports this possibility, although the precise mechanisms for an association between decreased ISCU expression and siderosis of trophoblasts warrant further biological and ultrastructural investigations.

The accumulation of intracellular iron and decreased Matrigel invasion after ISCU inhibition by shRNA transfection in Swan 71 trophoblasts strongly suggest that ISCU down-regulation by miR-210 could inhibit tropho- blastic invasion. A difference in the rate of positive Perls' reactions of the placental bed biopsy materials between control and preterm preeclampsia or SGA groups confined to preterm cases is consistent with the trajectory of placental miR-210 expression observed in the present study. It can be argued that the patient populations analyzed for placental miR-210 expression and trophoblastic iron deposition are different in this study. The populations were different because placental bed biopsy specimens were not available from those patients analyzed for placental miR-210 expression. However, we originally found increased placental miR-210 expression in women who were enrolled at the same institution where the cases used for iron staining in this study were also enrolled $^{27}$; thus, our observation of association between placental miR-210 and iron deposition is robust.

Recently, other investigators also have reported ISCU regulation by miR-210 in different systems. Fasanaro et al, ${ }^{56}$ using human embryonic kidney 293 cells, elegantly demonstrated ISCU mRNA among enriched mRNAs in an immunoprecipitated RNA-induced silencing complex with an MYC (alias c-myc)-tagged Ago2 and loaded with miR-210. Chan et $a^{57}$ confirmed that miR-210 regulation of ISCU in pulmonary arterial endothelial cells is important in mitochondrial metabolism. Increased miR-210 expression after hypoxia is expected to confer to the cells an adaptive survival advantage. In ischemic preconditioned bone marrow-derived mesenchymal stem cells, miR-210 protected the cells by targeting FLICE-associated huge protein/caspase-8-associated protein-2. ${ }^{58}$ ISCU regulation by miR-210 is also important in cancer biology, with prognostic implications. ${ }^{59,60}$ However, the findings in the present study clearly show that up-regulation of miR-210 can affect the critical biological features of the cells in distinct ways (eg, trophoblastic invasiveness necessary for successful placentation).

Histological changes of the placenta in preeclampsia and SGA pregnancies, particularly in cases of early-onset disease, ${ }^{12}$ have been largely attributed to maternal placental underperfusion. ${ }^{61}$ Burton et $\mathrm{al}^{62}$ recently showed that defective conversion of spiral arteries would lead to villous damage due to turbulent intervillous perfusion with high momentum, instead of compromising the total volume of blood flow, and to an increased risk of ischemia-reperfusion injury and oxidative stress due to spontaneous vasoconstriction. To our knowledge, we show for the first time that increased siderosis of interstitial trophoblasts at the placental bed is another novel pathological feature of preterm preeclampsia and SGA pregnancies. The presence of hemosiderin is generally considered as evidence of old hemorrhage, ${ }^{63}$ but our data strongly suggest that siderosis of interstitial trophoblasts is a consequence of nonhemorrhagic metabolic events, such as hypoxia and oxidative stress. Other studies also have shown both placental and systemic derangements of iron metabolism in preeclamptic patients. A microarray analysis of placental gene expression demonstrated higher expression of ceruloplasmin in patients with severe preeclampsia, compared with control cases. With proven ferroxidatic activity of this iron-transport protein, it was proposed that up-regulation of ceruloplasmin is a protective mechanism 
of the placenta against oxidative damage. ${ }^{64}$ Entman et al $^{65,66}$ reported elevated serum iron in preeclamptic patients, which they attributed to increased red blood cell turnover. Furthermore, serum levels of lipid peroxides, iron, and ceruloplasmin in severe preeclampsia are elevated, whereas the transferrin level was decreased; ischemic placental tissue was proposed to be a primary source of toxic iron in preeclampsia. ${ }^{67}$

There are limitations of this study. First, although we report a robust increase in miR-210 expression in the villous placental tissues of preterm preeclampsia and SGA cases, increased iron deposition in trophoblasts after hypoxia and ISCU knockdown was found only in Swan 71 cells with an extravillous trophoblast phenotype and in placental bed interstitial trophoblasts. Justification of our approach would require the demonstration of decreased $\mathrm{PO}_{2}$ at the placental bed in preterm preeclampsia and SGA cases. However, to our knowledge, information on placental bed $\mathrm{PO}_{2}$ in preeclampsia and SGA pregnancies is not available, whereas there are seminal works on placental and endometrial $\mathrm{PO}_{2}$ during pregnancy. ${ }^{68,69}$ Instead, pathological studies $^{70,71}$ have shown increased frequency of ischemic coagulation necrosis of the decidua, known as laminar necrosis or leukocytoclastic necrosis, in preeclampsia and SGA cases. This strongly suggests that metabolic stress is not restricted to the villous placenta but affects uteroplacental compartments, such as the decidua and the placental bed. In particular, Goldenberg et $\mathrm{al}^{70}$ have shown, in their analysis of 446 placentas obtained from consecutive singleton preterm births between 23 and 32 weeks of gestation, that women with diffuse decidual leukocytoclastic necrosis of the decidua basalis are more likely to have preeclampsia than others and that birth weight is significantly lower in diffuse decidual leukocytoclastic necrosis-positive cases compared with diffuse decidual leukocytoclastic necrosis-negative cases. Our data also suggest that there is a difference in the susceptibility to perturbation in iron metabolism between villous and extravillous trophoblasts. Second, we could not confirm the relationship between HIF- $1 \alpha$ and miR-210 expression levels in the placenta. We have tried immunohistochemical localization of HIF-1 $\alpha$ in 41 cases of preterm preeclampsia, with and without SGA, and none of the cases showed significant immunoreactivity regardless of miR-210 expression level (data not shown). Third, although we propose that iron deposition in interstitial trophoblasts is involved in the pathogenesis of preterm preeclampsia and SGA pregnancies, it is possible that it is a consequence of defective placentation because we could not investigate first-trimester tissue samples. Finally, an evaluation of the effects of hypoxia in two cell lines in vitro might be a too simplistic approach, considering the controversies over the effects of hypoxia on trophoblast invasion and complexities regarding the regulation of oxygen tensions in vitro. ${ }^{72}$

Collectively, preterm preeclampsia and SGA pregnancies are unique examples of a human disorder with perturbed iron metabolism involving the interstitial trophoblasts at the fetomaternal interface because of epigenetic alterations of the placenta: up-regulation of miR-210 tar- geting ISCU. This feature seems to be another pathological difference between early- and late-onset preeclampsia and SGA pregnancies. The findings herein provide a novel pathophysiological link between dysregulated expression of placental miRNA and pathogenesis of disorders of deep placentation in human pregnancy.

\section{Acknowledgments}

We thank Dr. Gil Mor (Yale University School of Medicine, New Haven, CT) for providing Swan 71 trophoblast cells; the patients who agreed to participate in our studies; and the nurses, laboratory staff, and clinicians who made this study possible.

\section{References}

1. Bauer ST, Cleary KL: Cardiopulmonary complications of pre-eclampsia. Semin Perinatol 2009, 33:158-165

2. Sibai B, Dekker G, Kupferminc M: Pre-eclampsia. Lancet 2005, 365: 785-799

3. Germain SJ, Sacks GP, Sooranna SR, Sargent IL, Redman CW: Systemic inflammatory priming in normal pregnancy and preeclampsia: the role of circulating syncytiotrophoblast microparticles. J Immunol 2007, 178:5949-5956

4. Powers RW, Catov JM, Bodnar LM, Gallaher MJ, Lain KY, Roberts JM: Evidence of endothelial dysfunction in preeclampsia and risk of adverse pregnancy outcome. Reprod Sci 2008, 15:374-381

5. Levine RJ, Lam C, Qian C, Yu KF, Maynard SE, Sachs BP, Sibai BM, Epstein FH, Romero R, Thadhani R, Karumanchi SA: Soluble endoglin and other circulating antiangiogenic factors in preeclampsia. N Engl J Med 2006, 355:992-1005

6. Maynard SE, Min JY, Merchan J, Lim KH, Li J, Mondal S, Libermann TA, Morgan JP, Sellke FW, Stillman IE, Epstein FH, Sukhatme VP, Karumanchi SA: Excess placental soluble fms-like tyrosine kinase 1 (sFlt1) may contribute to endothelial dysfunction, hypertension, and proteinuria in preeclampsia. J Clin Invest 2003, 111:649-658

7. Venkatesha S, Toporsian M, Lam C, Hanai J, Mammoto T, Kim YM, Bdolah Y, Lim KH, Yuan HT, Libermann TA, Stillman IE, Roberts D, D'Amore PA, Epstein FH, Sellke FW, Romero R, Sukhatme VP, Letarte M, Karumanchi SA: Soluble endoglin contributes to the pathogenesis of preeclampsia. Nat Med 2006, 12:642-649

8. Brosens JJ, Pijnenborg R, Brosens IA: The myometrial junctional zone spiral arteries in normal and abnormal pregnancies: a review of the literature. Am J Obstet Gynecol 2002, 187:1416-1423

9. Khong TY, De Wolf F, Robertson WB, Brosens I: Inadequate maternal vascular response to placentation in pregnancies complicated by pre-eclampsia and by small-for-gestational age infants. $\mathrm{Br} \mathrm{J}$ Obstet Gynaecol 1986, 93:1049-1059

10. Pijnenborg R, Anthony J, Davey DA, Rees A, Tiltman A, Vercruysse L, van Assche A: Placental bed spiral arteries in the hypertensive disorders of pregnancy. Br J Obstet Gynaecol 1991, 98:648-655

11. Starzyk KA, Salafia CM, Pezzullo JC, Lage JM, Parkash V, Vercruysse L, Hanssens M, Pijnenborg R: Quantitative differences in arterial morphometry define the placental bed in preeclampsia. Hum Pathol 1997, 28:353-358

12. Huppertz B: Placental origins of preeclampsia: challenging the current hypothesis. Hypertension 2008, 51:970-975

13. Redman CW, Sargent IL: Placental stress and pre-eclampsia: a revised view. Placenta 2009, 30(Suppl A):S38-S42

14. Yung HW, Calabrese S, Hynx D, Hemmings BA, Cetin I, CharnockJones DS, Burton GJ: Evidence of placental translation inhibition and endoplasmic reticulum stress in the etiology of human intrauterine growth restriction. Am J Pathol 2008, 173:451-462

15. Groom KM, Poppe KK, North RA, McCowan LM: Small-for-gestational-age infants classified by customized or population birthweight centiles: impact of gestational age at delivery. Am J Obstet Gynecol 2007, 197:239.e1-e5 
16. Brosens I, Dixon HG, Robertson WB: Fetal growth retardation and the arteries of the placental bed. Br J Obstet Gynaecol 1977, 84:656-663

17. Xiao R, Sorensen TK, Williams MA, Luthy DA: Influence of preeclampsia on fetal growth. J Matern Fetal Neonatal Med 2003, 13:157-162

18. Gupta M, Brewer G: MicroRNAs: new players in an old game. Proc Natl Acad Sci U S A 2006, 103:3951-3952

19. Kim VN, Nam JW: Genomics of microRNA. Trends Genet 2006 , 22:165-173

20. Avissar M, Christensen BC, Kelsey KT, Marsit CJ: MicroRNA expression ratio is predictive of head and neck squamous cell carcinoma. Clin Cancer Res 2009, 15:2850-2855

21. Camps C, Buffa FM, Colella S, Moore J, Sotiriou C, Sheldon H, Harris AL, Gleadle JM, Ragoussis J: hsa-miR-210 is induced by hypoxia and is an independent prognostic factor in breast cancer. Clin Cancer Res 2008, 14:1340-1348

22. Childs G, Fazzari M, Kung G, Kawachi N, Brandwein-Gensler M, McLemore M, Chen Q, Burk RD, Smith RV, Prystowsky MB, Belbin TJ, Schlecht NF: Low-level expression of microRNAs let-7d and miR-205 are prognostic markers of head and neck squamous cell carcinoma. Am J Pathol 2009, 174:736-745

23. Flavin RJ, Smyth PC, Finn SP, Laios A, O'Toole SA, Barrett C, Ring M, Denning KM, Li J, Aherne ST, Aziz NA, Alhadi A, Sheppard BL, Loda M, Martin C, Sheils OM, O'Leary JJ: Altered elF6 and Dicer expression is associated with clinicopathological features in ovarian serous carcinoma patients. Mod Pathol 2008, 21:676-684

24. Merritt WM, Lin YG, Han LY, Kamat AA, Spannuth WA, Schmandt R, Urbauer D, Pennacchio LA, Cheng JF, Nick AM, Deavers MT, Mourad-Zeidan A, Wang H, Mueller P, Lenburg ME, Gray JW, Mok S, Birrer MJ, Lopez-Berestein G, Coleman RL, Bar-Eli M, Sood AK: Dicer, Drosha, and outcomes in patients with ovarian cancer. N Engl J Med 2008, 359:2641-2650

25. Yu Z, Willmarth NE, Zhou J, Katiyar S, Wang M, Liu Y, Mccue PA, Quong AA, Lisanti MP, Pestell RG: microRNA 17/20 inhibits cellular invasion and tumor metastasis in breast cancer by heterotypic signaling. Proc Natl Acad Sci U S A 2010, 107:8231-8236

26. Yu Z, Baserga R, Chen L, Wang C, Lisanti MP, Pestell RG: microRNA, cell cycle, and human breast cancer. Am J Pathol 2010, 176:10581064

27. Pineles BL, Romero R, Montenegro D, Tarca AL, Han YM, Kim YM, Draghici S, Espinoza J, Kusanovic JP, Mittal P, Hassan SS, Kim CJ: Distinct subsets of microRNAs are expressed differentially in the human placentas of patients with preeclampsia. Am J Obstet Gynecol 2007, 196:261.e1-e6

28. Zhu XM, Han T, Sargent IL, Yin GW, Yao YQ: Differential expression profile of microRNAs in human placentas from preeclamptic pregnancies vs normal pregnancies. Am J Obstet Gynecol 2009, 200 661.e1-e7

29. Ivan M, Harris AL, Martelli F, Kulshreshtha R: Hypoxia response and microRNAs: no longer two separate worlds. J Cell Mol Med 2008, $12: 1426-1431$

30. Crosby ME, Kulshreshtha R, Ivan M, Glazer PM: MicroRNA regulation of DNA repair gene expression in hypoxic stress. Cancer Res 2009, 69:1221-1229

31. Huang X, Ding L, Bennewith KL, Tong RT, Welford SM, Ang KK, Story M, Le QT, Giaccia AJ: Hypoxia-inducible mir-210 regulates normoxic gene expression involved in tumor initiation. Mol Cell 2009, 35:856867

32. Zamudio S, Wu Y, letta F, Rolfo A, Cross A, Wheeler T, Post M, Illsley NP, Caniggia I: Human placental hypoxia-inducible factor-1alpha expression correlates with clinical outcomes in chronic hypoxia in vivo. Am J Pathol 2007, 170:2171-2179

33. ACOG Committee on Practice Bulletins-Obstetrics: ACOG practice bulletin: diagnosis and management of preeclampsia and eclampsia. Obstet Gynecol 2002, 99:159-167

34. Alexander GR, Himes JH, Kaufman RB, Mor J, Kogan M: A United States national reference for fetal growth. Obstet Gynecol 1996 $87: 163-168$

35. Gonzalez RP, Gomez RM, Castro RS, Nien JK, Merino PO, Etchegaray $A B$, Carstens MR, Medina LH, Viviani PG, Rojas IT: A national birth weight distribution curve according to gestational age in Chile from 1993 to 2000. Rev Med Chil 2004, 132:1155-1165

36. Straszewski-Chavez SL, Abrahams VM, Alvero AB, Aldo PB, Ma Y, Guller S, Romero R, Mor G: The isolation and characterization of a novel telomerase immortalized first trimester trophoblast cell line, Swan 71. Placenta 2009, 30:939-948

37. Kudo Y, Boyd CA, Kimura H, Cook PR, Redman CW, Sargent IL: Quantifying the syncytialisation of human placental trophoblast BeWo cells grown in vitro. Biochim Biophys Acta 2003, 1640:25-31

38. Orendi K, Gauster M, Moser G, Meiri H, Huppertz B: The choriocarcinoma cell line BeWo: syncytial fusion and expression of syncytiumspecific proteins. Reproduction 2010, 140:759-766

39. Babady NE, Carelle N, Wells RD, Rouault TA, Hirano M, Lynch DR, Delatycki MB, Wilson RB, Isaya G, Puccio $\mathrm{H}$ : Advancements in the pathophysiology of Friedreich's ataxia and new prospects for treatments. Mol Genet Metab 2007, 92:23-35

40. Camaschella C, Campanella A, De Falco L, Boschetto L, Merlini R, Silvestri L, Levi S, Iolascon A: The human counterpart of zebrafish shiraz shows sideroblastic-like microcytic anemia and iron overload. Blood 2007, 110:1353-1358

41. Mochel F, Knight MA, Tong WH, Hernandez D, Ayyad K, Taivassalo T, Andersen PM, Singleton A, Rouault TA, Fischbeck KH, Haller RG: Splice mutation in the iron-sulfur cluster scaffold protein ISCU causes myopathy with exercise intolerance. Am J Hum Genet 2008, 82:652-660

42. Olsson A, Lind L, Thornell LE, Holmberg M: Myopathy with lactic acidosis is linked to chromosome 12q23.3-24.11 and caused by an intron mutation in the ISCU gene resulting in a splicing defect. Hum Mol Genet 2008, 17:1666-1672

43. Hentze MW, Muckenthaler MU, Andrews NC: Balancing acts: molecular control of mammalian iron metabolism. Cell 2004, 117:285-297

44. Lieu PT, Heiskala M, Peterson PA, Yang Y: The roles of iron in health and disease. Mol Aspects Med 2001, 22:1-87

45. Rouault TA, Tong WH: Iron-sulfur cluster biogenesis and human disease. Trends Genet 2008, 24:398-407

46. Beinert $\mathrm{H}$, Holm RH, Munck E: Iron-sulfur clusters: nature's modular, multipurpose structures. Science 1997, 277:653-659

47. Johnson DC, Dean DR, Smith AD, Johnson MK: Structure, function, and formation of biological iron-sulfur clusters. Annu Rev Biochem 2005, 74:247-281

48. Tong WH, Rouault TA: Functions of mitochondrial ISCU and cytosolic ISCU in mammalian iron-sulfur cluster biogenesis and iron homeostasis. Cell Metab 2006, 3:199-210

49. Punga $T$, Bühler $M$ : Long intronic GAA repeats causing Friedreich ataxia impede transcription elongation. EMBO Mol Med 2010, 2:120-129

50. Li K, Tong WH, Hughes RM, Rouault TA: Roles of the mammalian cytosolic cysteine desulfurase, ISCS, and scaffold protein, ISCU, in iron-sulfur cluster assembly. J Biol Chem 2006, 281:1234412351

51. Iancu TC: Ferritin and hemosiderin in pathological tissues. Electron Microsc Rev 1992, 5:209-229

52. Richardson DR, Lane DJ, Becker EM, Huang ML, Whitnall M, Rahmanto YS, Sheftel AD, Ponka P: Mitochondrial iron trafficking and the integration of iron metabolism between the mitochondrion and cytosol. Proc Natl Acad Sci U S A 2010, 107:10775-10782

53. Nie G, Sheftel AD, Kim SF, Ponka P: Overexpression of mitochondrial ferritin causes cytosolic iron depletion and changes cellular iron homeostasis. Blood 2005, 105:2161-2167

54. Oh SY, Choi SJ, Kim KH, Cho EY, Kim JH, Roh CR: Autophagy-related proteins, LC3 and Beclin-1, in placentas from pregnancies complicated by preeclampsia. Reprod Sci 2008, 15:912-920

55. Kurz T, Terman A, Gustafsson B, Brunk UT: Lysosomes in iron metabolism, ageing and apoptosis. Histochem Cell Biol 2008, 129:389-406

56. Fasanaro P, D'Alessandra Y, DiStefano V, Melchionna R, Romani S, Pompilio G, Capogrossi MC, Martelli F: MicroRNA-210 modulates endothelial cell response to hypoxia and inhibits the receptor tyrosine kinase ligand Ephrin-A3. J Biol Chem 2008, 283:15878-15883

57. Chan SY, Zhang YY, Hemann C, Mahoney CE, Zweier JL, Loscalzo J: MicroRNA-210 controls mitochondrial metabolism during hypoxia by repressing the iron-sulfur cluster assembly proteins ISCU1/2. Cell Metab 2009, 10:273-284

58. Kim HW, Haider HK, Jiang S, Ashraf M: Ischemic preconditioning augments survival of stem cells via miR-210 expression by targeting caspase-8-associated protein 2. J Biol Chem 2009, 284:3316133168

59. Chen Z, Li Y, Zhang H, Huang P, Luthra R: Hypoxia-regulated microRNA-210 modulates mitochondrial function and decreases ISCU and COX10 expression. Oncogene 2010, 29:4362-4368 
60. Favaro E, Ramachandran A, McCormick R, Gee H, Blancher C, Crosby M, Devlin C, Blick C, Buffa F, Li JL, Vojnovic B, Pires das Neves R, Glazer P, Iborra F, Ivan M, Ragoussis J, Harris AL: MicroRNA-210 regulates mitochondrial free radical response to hypoxia and krebs cycle in cancer cells by targeting iron sulfur cluster protein ISCU. PLoS One 2010, 5:e10345

61. Redline RW, Boyd T, Campbell V, Hyde S, Kaplan C, Khong TY, Prashner HR, Waters BL: Maternal vascular underperfusion: nosology and reproducibility of placental reaction patterns. Pediatr Dev Pathol 2004, 7:237-249

62. Burton GJ, Woods AW, Jauniaux E, Kingdom JC: Rheological and physiological consequences of conversion of the maternal spiral arteries for uteroplacental blood flow during human pregnancy. Placenta 2009, 30:473-482

63. Salafia CM, Lopez-Zeno JA, Sherer DM, Whittington SS, Minior VK, Vintzileos AM: Histologic evidence of old intrauterine bleeding is more frequent in prematurity. Am J Obstet Gynecol 1995, 173:10651070

64. Guller S, Buhimschi CS, Ma YY, Huang ST, Yang L, Kuczynski E, Zambrano E, Lockwood CJ, Buhimschi IA: Placental expression of ceruloplasmin in pregnancies complicated by severe preeclampsia. Lab Invest 2008, 88:1057-1067

65. Entman SS, Moore RM, Richardson LD, Killam AP: Elevated serum iron in toxemia of pregnancy. Am J Obstet Gynecol 1982, 143:398-404
66. Entman SS, Kambam JR, Bradley CA, Cousar JB: Increased levels of carboxyhemoglobin and serum iron as an indicator of increased red cell turnover in preeclampsia. Am J Obstet Gynecol 1987, 156:11691173

67. Serdar Z, Gur E, Develioglu O: Serum iron and copper status and oxidative stress in severe and mild preeclampsia. Cell Biochem Funct 2006, 24:209-215

68. Jauniaux E, Watson A, Burton G: Evaluation of respiratory gases and acid-base gradients in human fetal fluids and uteroplacental tissue between 7 and 16 weeks' gestation. Am J Obstet Gynecol 2001, 184:998-1003

69. Rodesch F, Simon P, Donner C, Jauniaux E: Oxygen measurements in endometrial and trophoblastic tissues during early pregnancy. Obstet Gynecol 1992, 80:283-285

70. Goldenberg RL, Faye-Petersen O, Andrews WW, Goepfert AR, Cliver SP, Hauth JC: The Alabama Preterm Birth Study: diffuse decidual leukocytoclastic necrosis of the decidua basalis, a placental lesion associated with preeclampsia, indicated preterm birth and decreased fetal growth. J Matern Fetal Neonatal Med 2007, 20:391-395

71. Stanek J, Al-Ahmadie HA: Laminar necrosis of placental membranes: a histologic sign of uteroplacental hypoxia. Pediatr Dev Pathol 2005 , 8:34-42

72. Tuuli MG, Longtine MS, Nelson DM: Review: oxygen and trophoblast biology: a source of controversy. Placenta 2011, 32(Suppl 2):S109-S118 